\title{
Delayed Post Pancreatectomy Hemorrhage: Incidence, Clinical Characteristics, Risk Factors and Management
}

\section{A Ben Yehuda ${ }^{1}$, E Nizri1*, Y Goychman ${ }^{1}$, I Korry ${ }^{2}$, N Lubezky ${ }^{1}$, G Lahat ${ }^{1,3}$, I Nachmany ${ }^{1}$, J Klausner ${ }^{1,3}$ and M Ben Haim ${ }^{1,3}$}

${ }^{1}$ Department of General surgery, Tel- Aviv Sourasky Medical Center, Tel- Aviv, Israel

${ }^{2}$ Department of Radiology, Tel-Aviv Sourasky Medical Center, Tel-Aviv, Israel

${ }^{3}$ The Sackler Faculty of Medicine, Tel- Aviv University, Tel- Aviv, Israel

\begin{abstract}
Background: Delayed Post Pancreatectomy Hemorrhage (DPPH) is a devastating complication of pancreatic surgery, with a mortality rate approaching $50 \%$. Clinical predictors and an effective management modality could improve patient outcome, but currently are not fully established.
\end{abstract}

Aim: To define clinical predictors, treatment modalities and outcomes of DPPH

Methods: We retrospectively evaluated all pancreatic resections conducted in our center during 2008-2013 for delayed PPH. Indications for surgery, operative and post-operative course were reviewed. Methods implied for bleeding control and overall outcome are reported here.

Results: Of 403 pancreatic resections performed between 2008-2013, we report 10 cases of severe DPPH (2.5\%). Mortality rate was $50 \%$, which yielded $50 \%$ of the overall (90 days) mortality in this cohort. In all cases, pancreatic fistula, sepsis and sentinel bleeding were documented before hemorrhage. CT angiography (CTA) failed to diagnose bleeding or pseudo aneurism in 3 cases. In 8 patients, the intervention to control bleeding was by interventional radiology (IR) (embolization or stenting) without (6/8) or with (2/8) re-laparotomy. IR procedures were performed and successful even in face of hemodynamic instability. Length of hospital stay was increased and patients had high rate of septic episodes.

Conclusion: DPPH is a leading cause of mortality in pancreatic surgery. High index of suspicion in the appropriate setting and identification of sentinel bleeding are the keys for diagnosis and early management. IR may be used as both the diagnostic tool and treatment modality even in unstable patients.

\section{Background}

Pancreatic resection and especially pancreaticoduodenectomy (PD) is considered a complex operation, previously notorious for high perioperative morbidity and mortality rates. However, while the perioperative mortality of PD was over $15 \%$ in the 70 's, it is now days less than $4 \%$ [1-7]. One of the most important reasons for this improvement is the greater experience of a limited number of surgeons who perform the procedure on a regular basis in high-volume referral centers [8-11]. Combined pancreatic resection and vascular reconstruction prevalence is rising. As expected, these patients have a higher morbidity and mortality rate in comparison to conventional PD (39.9\% vs.33.3\% and $5.7 \%$ vs. $2.9 \%$, respectively) [12].

In spite of the impressive progress made in recent years in perioperative morbidity and mortality, a pancreatic fistula as a postoperative complication occurs in as high as $22 \%$ of cases [13]. Pancreatic fistulas can lead to sepsis and hemorrhage if not adequately drained. These complications are associated with mortality of 20 to $40 \%$, prolonged hospitalization, and increased hospital expenses [14].

Post pancreatectomy hemorrhage $(\mathrm{PPH})$ is a term used for all bleeding episodes post pancreatic surgery. It is further divided according to the time of onset post operatively (delayed: $>24$ hrs postoperatively), location (intra/extraluminal, anastomotic origin) and severity of bleeding (severe PPH defined as hemoglobin drop $>3 \mathrm{gr} /$ $\mathrm{dl}$, hemodynamic instability or need for intervention) [15]. Prevalence of $\mathrm{PPH}$ is $5.5 \%$, equally distributed among different indications for surgery (malignancies, borderline tumors, and focal pancreatitis). In an era of increased number of PD with vascular reconstruction, it is expected that the incidence of $\mathrm{PPH}$ will rise. In recent years an objective, universally accepted definition and clinical grading of $\mathrm{PPH}$ is adopted according to the International Study Group on Pancreatic surgery (ISGPS) [15].

$\mathrm{PPH}-$ related overall mortality is $16-20 \%$ and raises to about $50 \%$ among the subgroup of DPPH secondary to pseudoaneurysm (PSA) or vascular erosion [16]. PSA exists when a normal arterial wall is replaced by fibrous tissue due to mechanical (iatrogenic) or chemical (by pancreatic juice) injury. This PSA may further cause a life-threatening bleeding.

Clearly, some of the improvement in overall mortality after PD may be attributed to the post-operative management of complications. In this aspect, the considerable advances in invasive radiological techniques enable control of DPPH and reduce the need for re-laparotomy with its significant sequela [15].

This study describes our experience in the management of DPPH with focus on risk factors and management.

*Corresponding author: Eran Nizri, MD, PhD, Department of General surgery, Tel- Aviv Sourasky Medical Center, Tel- Aviv, Israel, Tel: 972-524266107; Email: erann@tlvmc.gov.il

Received January 25, 2014; Accepted May 19, 2014; Published May 22, 2014

Citation: Yehuda AB, Nizri E, Goychman Y, Korry I, Lubezky N, et al. (2014) Delayed Post Pancreatectomy Hemorrhage: Incidence, Clinical Characteristics, Risk Factors and Management. J Vasc Med Surg 2: 139. doi: 10.4172/23296925.1000139

Copyright: (c) 2014 Yehuda AB, et al. This is an open-access article distributed under the terms of the Creative Commons Attribution License, which permits unrestricted use, distribution, and reproduction in any medium, provided the original author and source are credited. 
Citation: Yehuda AB, Nizri E, Goychman Y, Korry I, Lubezky N, et al. (2014) Delayed Post Pancreatectomy Hemorrhage: Incidence, Clinical Characteristics, Risk Factors and Management. J Vasc Med Surg 2: 139. doi: 10.4172/2329-6925.1000139

Page 2 of 5

\begin{tabular}{|c|c|c|c|c|c|c|c|c|c|}
\hline case & Age/gender & Index operation & Pathology & $\begin{array}{r}\text { Pancreatic } \\
\square\end{array}$ & Bacteriology & $\begin{array}{l}\text { Timing of } \\
\text { Sentinel } \\
\text { bleeding } \\
\text { (POD) }\end{array}$ & $\begin{array}{l}\text { Timing of } \\
\text { DPPH } \\
\text { (POD) }\end{array}$ & $\begin{array}{c}\text { Bleeding site } \\
\text { (Intra/extra luminal) }\end{array}$ & $\begin{array}{l}\text { Number of } \\
\text { Packed cells } \\
\text { transfused }\end{array}$ \\
\hline 1 & $57 / \mathrm{M}$ & PD & IPMN & + & Klebsiella Pneumonia & 10 & 12 & both & 19 \\
\hline 2 & 70/M & $\begin{array}{l}\text { DP } \\
\text { PV resection }\end{array}$ & $A C$ & + & Proteus Mirabillis & 13 & 14 & both & 11 \\
\hline 3 & $58 / \mathrm{M}$ & Enucleation & NET & + & $\begin{array}{l}\text { Pseudomonas } \\
\text { Aeroginosa }\end{array}$ & 5 & 5 & extra luminal & 12 \\
\hline 4 & $67 / \mathrm{M}$ & $\begin{array}{c}\text { DP } \\
\text { PV resection } \\
\text { CHA resection }\end{array}$ & $A C$ & + & Klebsiella Pneumonia & 15 & 17 & extra luminal & 6 \\
\hline 5 & $80 / \mathrm{M}$ & $\begin{array}{l}\text { Enucleation } \\
\text { Hepatectomy }\end{array}$ & CC & + & $\begin{array}{l}\text { Staphylococcus } \\
\text { Aureus }\end{array}$ & 17 & 17 & extra luminal & 14 \\
\hline 6 & $58 / \mathrm{M}$ & PD & AC & + & - & 16 & 17 & intra luminal & 4 \\
\hline 7 & $64 / \mathrm{M}$ & PD & AC & + & - & 17 & 18 & extra luminal & 15 \\
\hline 8 & $67 / \mathrm{M}$ & PD & CC & + & $\begin{array}{l}\text { Klebsiella Pneumonia } \\
\text { Enterococcus } \\
\text { Faecalis }\end{array}$ & 10 & 11 & both & \\
\hline 9 & $62 / \mathrm{M}$ & PD & $A C$ & + & E.coli & 13 & 13 & both & 3 \\
\hline 10 & $56 / \mathrm{M}$ & PD & $A C$ & + & $\begin{array}{l}\text { Enterococcus } \\
\text { Faecalis }\end{array}$ & 10 & 10 & both & 0 \\
\hline
\end{tabular}

AC: Adenocarcinoma; CC: Cholangiocarcinoma; CHA: Common Hepatic Artery; DP: Distal Pancreatectomy; DPPH: Delayed Post Pancreatectomy Hemorrhage; IPMN: Intraductal Papillary Mucinous Neoplasm; M: Male; NET: Neuroendocrine Tumor; PD: Pancreaticoduodencetomy; POD: Post-operative Day; PV: Portal Vein Table 1: Patients and clinical characteristics of Delayed Post Pancreatectomy Hemorrhage.

\section{Methods}

We retrospectively analyzed our prospectively collected data on all pancreatic resections preformed in our center during the time period of January 2008 to December 2013. This study was approved by the Institutional Ethic Board. All pancreatic resections files (403) were reviewed for preoperative demographics and comorbidities, patient operative course and post-operative complications including postoperative imaging studies and final pathology report.

\section{DPPH}

PPH was defined according to the ISGPS commonly used criteria. Briefly DPPH is defined as either intra or extra-luminal bleeding more than 24 hrs post-surgery. When it is accompanied by hemoglobin concentration drop of $>3 \mathrm{~g} / \mathrm{dl}$ and a circulatory impairment requiring medical intervention it is defined a grade $\mathrm{C}$ hemorrhage. In the cohort 21 bleeding events were recorded: 7 early bleeding events and 14 late. 3/7 with early $\mathrm{PPH}$ had grade $\mathrm{C}$ bleeding event and were re-operated in POD 0 . The rest of the early PPH had grade B hemorrhage (in nasogastric tube aspirate and external drains). 4 of $\mathrm{DPPH}$ were grade $\mathrm{B}$ hemorrhages that were proved to bleed from gastro-jejunal anastomosis by endoscopy. Our study which focuses on PPH due to PSA or vascular erosion deals with grade C DPPH according to the ISGPS definitions. We also included cases in which active bleeding were demonstrated by angiography.

\section{Pancreatic fistula}

Pancreatic leak was defined by 3 times or more increased amylase content in secretions of external drains (in comparison to plasma) after post-operative day (POD) 3 [17].

\section{Sentinel bleeding}

Sentinel bleeding is defined as a preliminary warning bleeding that precedes a major hemorrhage $[18,19]$. This sentinel bleeding probably indicates local infection and an anastomotic leak [18].

\section{Diagnosis and treatment of choice}

The decision upon management of post pancreatectomy bleeding in this study is based on a clinical evaluation and judgment of 4 senior experienced pancreatic surgeons.

\section{Visceral angiography}

Transfemoral visceral angiography and embolization were performed by experienced IRs. The preferred technique of super selective embolization was employed with stainless steel coils placed proximal to the arterial wall defect or within the aneurysm itself. Coils were placed using a coil pusher or via a flushing method. Alternatively, bridging stent grafts were used.

\section{Results}

\section{Study population}

Within this time period, 403 pancreatic resections were performed: 237 pancreaticoduodenectomies, 135 distal pancreatectomies (including 33 laparoscopic), 12 total pancreatectomies, 8 enucleations and 9 transdeudenal papillectomies. 8 patients died within 30 days after surgery and 2 more died within 60 days (mortality rates, $2 \%$ and $2.5 \%$, respectively). These rates compare favorably with results published by other groups [1-7].

\section{Incidence and clinical characteristics of DPPH}

We identified 10 patients with DPPH, which yields a $2.5 \%$ incidence of this dreadful complication. Patient's characteristics are described in table 1 . Interestingly, all cases were male, in comparison to equal gender distribution ( $49 \%$ males and $51 \%$ females) in the whole cohort of pancreatic resections. In all DPPH cases, pancreatic leak was diagnosed before hemorrhage. The leak was classified as grade $\mathrm{C}$ in $80 \%$ of the patients (due to septic course) and grade B in $20 \%$ (due to peri-pancreatic collection) [17]. The bleeding event reclassified all our DPPH patients to grade C. In the cohort an overall $25 \%$ of pancreatic leak was diagnosed; $10 \%$ were grade $\mathrm{A}$ leak and the rest were $\mathrm{B}$ and C. Drain culture was positive in all cases classified as grade $\mathrm{C}$ cases prior to bleeding.

The bleeding occurred on POD 5 to POD 18, preceded by sentinel bleeding few hours to $48 \mathrm{hrs}$ prior to the bleeding event in all cases 
Citation: Yehuda AB, Nizri E, Goychman Y, Korry I, Lubezky N, et al. (2014) Delayed Post Pancreatectomy Hemorrhage: Incidence, Clinical Characteristics, Risk Factors and Management. J Vasc Med Surg 2: 139. doi: 10.4172/2329-6925.1000139

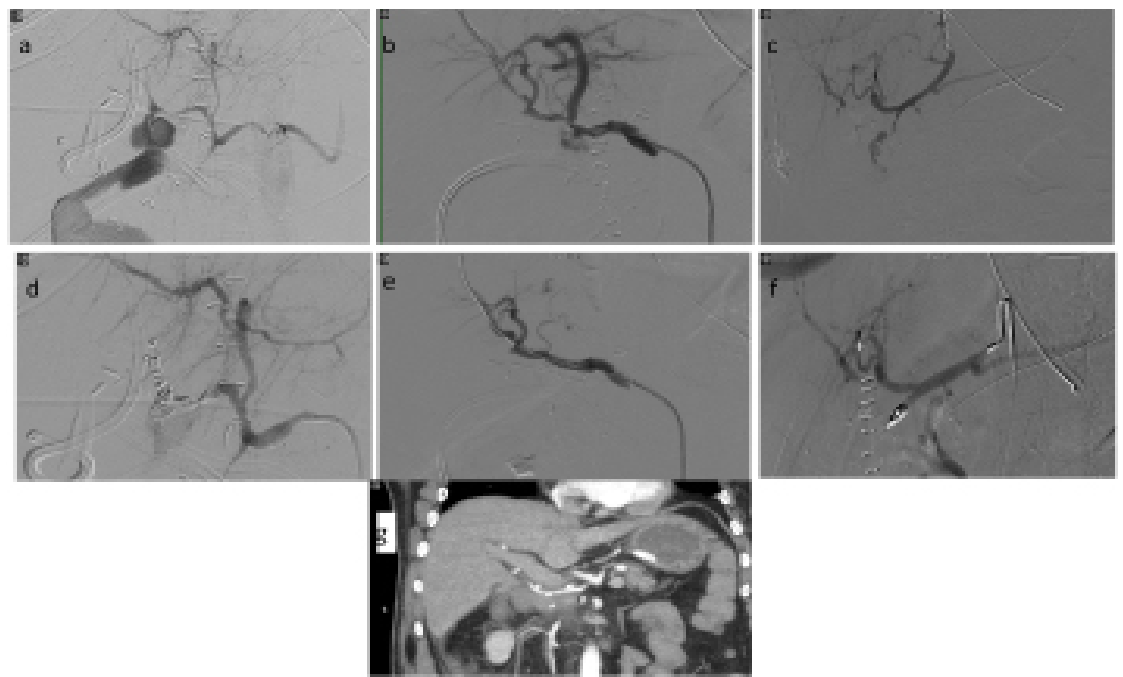

Figure 1: Irregularity of the GDA stump as demonstrated by CTA, a. Bleeding from the Rt hepatic artery, b. Bleeding from the short GDA stump c. Bleeding from the GDA, d. Coiling of the Rt hepatic artery, e. GDA covering by common hepatic artery stent graft, f. Coiling of the GDA.

\begin{tabular}{|c|c|c|c|c|c|c|}
\hline case & $\begin{array}{l}\text { Bleeding vessel } \\
\text { (as diagnosed by } \\
\text { angiography) }\end{array}$ & Interventions & Post intervention complication & $\begin{array}{l}\text { Post bleeding LOS } \\
\text { (days) }\end{array}$ & $\begin{array}{l}\text { Total LOS } \\
\text { (days) }\end{array}$ & Outcome \\
\hline 1 & GDA & Embolization, GDA & None & 14 & 26 & Alive \\
\hline 2 & GDA & Laparotomy & Sepsis, MOF & 2 & 16 & Died \\
\hline 3 & PDA & Embolization, PDA & Sepsis, MOF & 39 & 44 & Died \\
\hline 4 & RGE & Embolization, RGE & Sepsis, respiratory failure & 46 & 63 & Alive \\
\hline 5 & RHA & $\begin{array}{c}\text { Aortic occlusion } \\
\text { (angiographic) } \\
\text { Embolization, RHA }\end{array}$ & $\begin{array}{c}\text { ACS } \\
\text { Traumatic dissection of EIA }\end{array}$ & 0 & 17 & Died \\
\hline 6 & $?$ & - & $\begin{array}{l}\text { Hemorrhagic shock } \\
\text { Exsanguination }\end{array}$ & 0 & 17 & Died \\
\hline 7 & PDA & Embolization, PDA & None & 7 & 25 & Alive \\
\hline 8 & $?$ & $\begin{array}{c}\text { Laparotomy Thoracotomy } \\
\text { aortic clamp }\end{array}$ & $\begin{array}{l}\text { Hemorrhagic shock } \\
\text { Exsanguination }\end{array}$ & 0 & 11 & Died \\
\hline 9 & GDA & Embolization, $\mathrm{CHA}$ & Sepsis & 32 & 46 & Alive \\
\hline 10 & GDA & Stent graft, $\mathrm{CHA}$ & Delayed Gastric Emptying & 21 & 31 & Alive \\
\hline
\end{tabular}

ACS: Abdominal Compartment Syndrome; CHA: Common Hepatic Artery; EIA: External

Iliac Artery; GDA: Gastroduodenal Artery; LOS: Length of Stay; PDA: Pancreaticodeudenal Artery; RGE: Rt Gastroepiploic Artery; RHA: Rt Hepatic Artery; MOF: Multi Organ Failure

Table 2: Interventions and outcome.

as shown in table 1 . The presentation of bleeding was either extra luminal (via drains and or to the abdominal cavity- 4 patients), intra luminal (hematemesis or via nasogastric tube- 1 patient) or combined (5 patients).

\section{Diagnosis}

Principally, the diagnosis was pure clinical. Of note are 3 cases in which CTA following sentinel bleeding failed to demonstrate active bleeding or PSA, later found during angiography.

\section{Management}

In 7 patients, interventional radiology (IR) was the primary initial treatment, 2 were rushed to the operating room and one died in the ICU before any definitive therapeutic effort could be done. The decision to operate was influenced by a combination of bleeding and enteric leak in one case, and vascular reconstruction and presumed venous bleeding in the other. Four out of 7 patients were transferred to the IR suite while hemodynamically unstable and on vasopressor support. A decision which may contradict basic surgical principles, but was found to be effective (3/4 survived vs. 0/2 survivors when surgery was applied).

Figure 1 shows the different invasive radiology techniques employed for bleeding control. These included coiling of the bleeding branch or of the feeding source and stenting (usually with bridging stents). Angiographic findings, i.e. bleeding source, and procedures performed are detailed in table 2. 2/8 patients needed re-angiography due to recurrent bleeding after the first procedure.

\section{Outcomes}

The outcomes of delayed PPH are quite gloom as shown in table 2. Overall, this complication harbor $50 \%$ mortality rate $(n=5)$ with prolongation of hospital stay among the entire group (average of 38 days, in comparison to other pancreatic resections, 9.5 days). Among the survivors of DPPH: 2 year survival of $80 \%$ (comparable to the cohort), readmission rate of $40 \%$ in the first year after operation (cholangitis, small bowel obstruction due to post-operative ventral hernia). 
Citation: Yehuda AB, Nizri E, Goychman Y, Korry I, Lubezky N, et al. (2014) Delayed Post Pancreatectomy Hemorrhage: Incidence, Clinical Characteristics, Risk Factors and Management. J Vasc Med Surg 2: 139. doi: 10.4172/2329-6925.1000139

\section{Discussion}

This study demonstrates the impact of DPPH on post pancreatectomy mortality. Similar high rate is also reported by others $[20,16]$.

Clinically, the presentation of PPH can be either as gastrointestinal bleeding (in nasogastric tubes), as an intra-abdominal bleeding (in external drains) or both. This variation of bleeding manifestation is attributed to the presence of pancreatic fistula which creates a communication of the abdominal cavity to the intraluminal space.

All cases in our series demonstrated an event of sentinel bleeding, which actually pose a diagnostic opportunity. When it was promptly investigated by formal angiography or computed tomography angiography (CTA) an improvement in outcome is noticed $(2 / 2$ cases survived, with only minor morbidity of delayed gastric emptying in one of the two). However, all bleeding events in our patients rose from the celiac trunk which makes CTA useless for bleeding localization. Moreover, in 3 cases CTA failed to demonstrate active bleeding or a PSA. Altogether, these data raise the possibility to directly evaluate sentinel bleeding by angiography, omitting CTA, especially in high risk setting (like in pancreatic fistula). It may also be prudent to evaluate for PSA in high risk cases (e.g. pancreatic fistula and vascular reconstruction) in the appropriate time course even in the absence of sentinel bleeding. In summary, due to the high mortality rate of DPPH, we suggest a liberal use of angiography or imaging in high risk settings. Clearly, further research should be carried before a firm conclusion is reached.

As mentioned above, all cases of DPPH had a pancreatic fistula. At least 4 of the patients had low output fistula so that a link between volume of drainage and DPPH could not be established. Organisms cultured in our patients represent common bowel flora. This stands in contrast to a previous report which stressed the role of S. Aureus on delayed PPH [21].

Interestingly, in this series all cases are males while in the cohort of pancreatic surgery they consist only $49 \%$ of all patients. This male tendency had not been previously reported though higher male ratio is found in previous series $[4,19,22]$. However, in light of the small sample size, this finding may be a sampling error.

The significant role of the IR in the management of DPPH is demonstrated once again in this work. None of the operated patients survived. Only patients who are bleeding could be controlled angiographically survived. Even hemodynamically unstable patients treated by IR approach had $75 \%$ survival. This was also reported by others [22,23]. Culminating evidence suggests that angiography is the preferred management option for DPPH. Under the limitations of small patient number and possible selection bias, the surgical dogma that hemodynamically instability mandates operation is once again confronted with the better outcome presented here by IR.

Our and others experience highlight again the key role of multidisciplinary expertise, experience, availability and resources needed to manage DPPH in the effort to minimize mortality following pancreatic surgery.

\section{Conclusion}

$\mathrm{DPPH}$ is a major source of post pancreatectomy mortality in recent years. This complication has a typical clinical scenario: a pancreatic leak and a sentinel bleeding event. This scenario affords an opportunity for early intervention by angiographic techniques. It seems that hemodynamic instability does not preclude effective angiographic intervention and according to published studies, is the only way to save patient life.

\section{References}

1. Balcom JHt, Rattner DW, Warshaw AL, Chang Y, Fernandez-del Castillo C (2001) Ten-year experience with 733 pancreatic resections: changing indications, older patients, and decreasing length of hospitalization. Arch Surg 136: 391-398.

2. Cameron JL, Pitt HA, Yeo CJ, Lillemoe KD, Kaufman HS, et al. (1993) One hundred and forty-five consecutive pancreaticoduodenectomies without mortality. Ann Surg 217: 430-435; discussion 435-438.

3. Crist DW, Sitzmann JV, Cameron JL (1987) Improved hospital morbidity, mortality, and survival after the Whipple procedure. Ann Surg 206: 358-365.

4. Kneuertz PJ, Pitt HA, Bilimoria KY, Smiley JP, Cohen ME, et al. (2012) Risk of morbidity and mortality following hepato-pancreato-biliary surgery. J Gastrointest Surg 16: 1727-1735.

5. Pellegrini CA, Heck CF, Raper S, Way LW (1989) An analysis of the reduced morbidity and mortality rates after pancreaticoduodenectomy. Arch Surg 124: 778-781.

6. Trede M, Schwall G, Saeger HD (1990) Survival after pancreatoduodenectomy. 118 consecutive resections without an operative mortality. Ann Surg 211: 447 458

7. Yeo CJ, Cameron JL, Sohn TA, Lillemoe KD, Pitt HA, et al. (1997) Six hundred fifty consecutive pancreaticoduodenectomies in the 1990s: pathology complications, and outcomes. Ann Surg 226: 248-257; discussion 257-260.

8. Bilimoria KY, Talamonti MS, Sener SF, Bilimoria MM, Stewart AK, et al. (2008) Effect of hospital volume on margin status after pancreaticoduodenectomy for cancer. J Am Coll Surg 207: 510-519.

9. Birkmeyer JD, Siewers AE, Finlayson EV, Stukel TA, Lucas FL, et al. (2002) Hospital volume and surgical mortality in the United States. N Engl J Med 346 1128-1137.

10. Birkmeyer JD, Stukel TA, Siewers AE, Goodney PP, Wennberg DE, et al. (2003) Surgeon volume and operative mortality in the United States. N Engl J Med 349: 2117-2127.

11. Birkmeyer JD, Warshaw AL, Finlayson SR, Grove MR, Tosteson AN (1999) Relationship between hospital volume and late survival after pancreaticoduodenectomy. Surgery 126: 178-183.

12. Castleberry AW, White RR, De La Fuente SG, Clary BM, Blazer DG, et al. (2012) The impact of vascular resection on early postoperative outcomes after pancreaticoduodenectomy: an analysis of the American College of Surgeons National Surgical Quality Improvement Program database. Ann Surg Oncol 19: 4068-4077.

13. Cullen JJ, Sarr MG, Ilstrup DM (1994) Pancreatic anastomotic leak after pancreaticoduodenectomy: incidence, significance, and management. Am J Surg 168: 295-298.

14. Lai EC, Lau SH, Lau WY (2009) Measures to prevent pancreatic fistula after pancreatoduodenectomy: a comprehensive review. Arch Surg 144: 1074-1080.

15. Wente MN, Veit JA, Bassi C, Dervenis C, Fingerhut A, et al. (2007) Postpancreatectomy hemorrhage (PPH): an International Study Group of Pancreatic Surgery (ISGPS) definition. Surgery 142: 20-25

16. Yekebas EF, Wolfram L, Cataldegirmen G, Habermann CR, Bogoevski D, et al (2007) Postpancreatectomy hemorrhage: diagnosis and treatment: an analysis in 1669 consecutive pancreatic resections. Ann Surg 246: 269-280.

17. Pratt WB, Maithel SK, Vanounou T, Huang ZS, Callery MP, et al. (2007) Clinical and economic validation of the International Study Group of Pancreatic Fistula (ISGPF) classification scheme. Ann Surg 245: 443-451.

18. Brodsky JT, Turnbull AD (1991) Arterial hemorrhage after pancreatoduodenectomy. The 'sentinel bleed'. Arch Surg 126: 1037-1040.

19. Otah E, Cushin BJ, Rozenblit GN, Neff R, Otah KE, et al. (2002) Visceral artery pseudoaneurysms following pancreatoduodenectomy. Arch Surg 137: 55-59.

20. Grutzmann R, Ruckert F, Hippe-Davies N, Distler M, Saeger HD (2012) Evaluation of the International Study Group of Pancreatic Surgery definition of post-pancreatectomy hemorrhage in a high-volume center. Surgery 151: 612 620. 
Citation: Yehuda AB, Nizri E, Goychman Y, Korry I, Lubezky N, et al. (2014) Delayed Post Pancreatectomy Hemorrhage: Incidence, Clinical Characteristics, Risk Factors and Management. J Vasc Med Surg 2: 139. doi: 10.4172/2329-6925.1000139

Page 5 of 5

21. Sanjay P, Fawzi A, Fulke JL, Kulli C, Tait IS, et al. (2010) Late post pancreatectomy haemorrhage. Risk factors and modern management. JOP 11: 220-225

22. Sanjay P, Kellner M, Tait IS (2012) The role of interventional radiology in the management of surgical complications after pancreatoduodenectomy. HPB (Oxford) 14: 812-817.
23. Fujii Y, Shimada H, Endo I, Yoshida K, Matsuo K, et al. (2007) Management of massive arterial hemorrhage after pancreatobiliary surgery: does embolotherapy contribute to successful outcome? J Gastrointest Surg 11: 432 438. 